\title{
Acoustic telemetry reveals strong spatial preferences and mixing during successive spawning periods in a partially migratory common bream population
}

\author{
Emily R. Winter ${ }^{1}\left[\right.$ ] Andrew M. Hindes ${ }^{2} \cdot$ Steve Lane $^{3} \cdot$ J. Robert Britton ${ }^{1}$
}

Received: 23 October 2020 / Accepted: 15 April 2021 / Published online: 10 May 2021

(c) The Author(s) 2021

\begin{abstract}
Partial migration, whereby a population comprises multiple behavioural phenotypes that each have varying tendencies to migrate, is common among many animals. Determining the mechanisms by which these phenotypes are maintained is important for understanding their roles in population structure and stability. The aim here was to test for the temporal and spatial consistency of migratory phenotypes in a common bream Abramis brama ('bream') population, and then determine their social preferences and extent of mixing across three successive annual spawning periods. The study applied passive acoustic telemetry to track the movements of bream in the River Bure system of the Norfolk Broads, a lowland wetland comprising highly connected riverine and lacustrine habitats. Analyses revealed that individual migratory phenotype was highly consistent across the 3 years, but this was not predicted by fish sex or length at tagging. During the annual spawning periods, network analyses identified off-channel areas visited by both resident and migrant fish that, in non-spawning periods, were relatively independent in their space use. Within these sites, the co-occurrence of bream was non-random, with individuals forming more preferred associations than expected by chance. These associations were not strongly predicted by similarity in fish length, sex or behavioural phenotype, indicating that the resident and migrant phenotypes mixed during their annual spawning periods. The results suggested these different phenotypes, with spatially distinct resource use in non-spawning periods, comprised a single population, with this having important implications for the management of this wetland resource.
\end{abstract}

Keywords Abramis brama $\cdot$ Migration $\cdot$ Phenotype $\cdot$ Residency $\cdot$ Social network

\section{Introduction}

Migration is a diverse phenomenon that exists across taxa and has a strong influence on ecological and evolutionary processes, ranging from the individual level up to whole ecosystem dynamics (Dingle 1996; Chapman et al. 2012a). Within species, movement strategies can vary between individuals, with only a proportion of a population being

Emily R. Winter

ewinter@bournemouth.ac.uk

1 Department of Life and Environmental Sciences, Faculty of Science and Technology, Bournemouth University, Poole BH12 5BB, UK

2 Fishtrack Ltd, 2 South End Farm Cottages, Beccles NR34 8TG, UK

3 Fisheries, Biodiversity and Geomorphology Team, Environment Agency, Dragonfly House, Norwich NR3 1UB, UK migratory. This is termed 'partial migration' and is widely documented in fishes at a variety of spatial scales (Chapman et al. 2012a), from small potamodromous habitat shifts ( $<5 \mathrm{~km}$; Brodersen et al. 2014) to large diadromous and marine migrations (100 s to $1000 \mathrm{~s} \mathrm{~km}$; Robichaud and Rose 2004; Augspurger et al. 2017; Ferguson et al. 2019). Understanding partial migration and its role in processes such as gene flow and adaptation is important for monitoring population stability and the conservation and management of species (Chapman et al. 2012a; Turbek et al. 2018).

Reproductive and genetic isolation of populations is one mechanism by which the coexistence of sympatric resident and migrant phenotypes can be maintained (e.g. Grabowski et al. 2011; Turbek et al. 2018; Whitlock et al. 2018). This may occur spatially, for example, with the segregation by depth of different migratory phenotypes of Atlantic cod Gardus morhua during spawning (Grabowski et al. 2011). Isolation can also be temporal, such as through the separation of the early and late spawning runs of kokanee 
salmon Oncorhynchus nerka (Whitlock et al. 2018). Yet, within populations, different migratory phenotypes can also simultaneously occur and interbreed, including where each behavioural type may produce progeny of the alternate form (e.g. Hodge et al. 2016). Thus, while spawning segregation can imply a strong heritability of migratory behaviour, as observed in some salmonid fishes (Berejikian et al. 2014; Debes et al. 2020), other factors such as body size, inter- and intrapopulation density, predation risk, temperature and/or resource availability may influence whether an individual fish undertakes a migration (Brodersen et al. 2011; Skov et al. 2011; Montorio et al. 2018). Across multiple years, the decision to migrate can depend on prevailing conditions, although in the cyprinid fish roach Rutilus rutilus, overwintering migratory strategy was largely consistent within individuals over time (Brodersen et al. 2014). The partial migration of this species has been intensely studied, but for other non-salmonid, potamodromous species, its prevalence and drivers remain largely unexplored (Chapman et al. 2012b). This is despite evidence of widespread ecological implications from fluctuating levels of fish movements, such as both bottom-up and top-down effects on trophic dynamics (Brodersen et al. 2011; Hansen et al. 2019).

The common bream Abramis brama ('bream') is a relatively large-bodied, laterally compressed, cyprinid fish that can exhibit partial migration (Whelan 1983; Skov et al. 2011; Brodersen et al. 2019). Bream typically mature at age 4-6 years, and adults can grow to more than $500 \mathrm{~mm}$ in length and live for at least 20 years (Backiel and Zawisza 1968; Kennedy and Fitzmaurice 1968). Reproductive periods occur in spring or early summer (April to June), most commonly as water temperatures increase above $12{ }^{\circ} \mathrm{C}$ (Backiel and Zawisza 1968). Eggs are deposited on spawning substrata, which generally include submerged macrophytes (e.g. Myriophyllum sp., Chara sp.) and roots (Backiel and Zawisza 1968; Pinder 1997). Bream can be found in a diverse array of freshwater, brackish, riverine and lacustrine habitats, but the extent of their movement between these habitats appears site specific, with some populations showing pronounced spring and autumn peaks of migration, while others remain largely resident year-round (Backiel and Zawisza 1968).

Within populations, the propensity of bream to migrate has been linked to size and predation risk, with smaller individuals more likely to seek refuge overwinter in shallow stream habitats (Skov et al. 2011). Elsewhere, in systems comprised of interconnected lakes, poor somatic condition may drive their partial nomadic movement between lakes (Brodersen et al. 2019). This arrhythmic type of movement suggests that populations in connected systems should be managed as one overall unit or metapopulation (Brodersen et al. 2019). Given that bream are important ecosystem engineers that can affect ecological stability, this has potentially important implications for the management of systems, including for nutrient dynamics and controlling eutrophication (Phillips and Jackson 1990). Nevertheless, few studies have assessed bream population structure in well-connected naturalised systems and with respect to the mechanisms by which different migratory phenotypes are maintained.

The Norfolk Broads is a protected wetland of high connectivity in eastern England (Natural England 2020). We infer from preliminary data that the bream population comprises diverse migratory phenotypes (including residents and migrants), forming spatially distinct sub-populations in non-reproductive periods (Winter et al. 2021a). While some of these sub-populations then make considerable migrations during their reproductive period, the extent of their spatial and social mixing during spawning remains unclear. This is a critical knowledge gap, as reproductive segregation could suggest that complex genetic processes drive their migratory behaviours and potentially indicate population divergence (Jorgensen et al. 2010; Baerwald et al. 2016). Consequently, through the application of passive acoustic telemetry across three spawning periods, we aimed to investigate the temporal and spatial consistency of migratory phenotypes in the bream population and identify the extent of their reproductive mixing. Accordingly, the objectives were to: (1) evaluate individual consistency in migration strategy (resident/ migrant) and examine the influence of length and sex on movement type; (2) assess the spatial preferences of bream in their reproductive period (as 'hotspots' of bream detection across the acoustic receiver network); and (3) evaluate the social preferences of bream in their reproductive period, identifying whether their similarity in length, sex or movement type influenced their probability of interaction in time and space.

\section{Materials and methods}

\section{Study area}

The study system was the northern area of the Broads National Park, a lowland wetland in eastern England comprised of the main River Bure, its two tributaries the Rivers Ant and Thurne, plus numerous interconnected dykes and small shallow interconnected lakes (medieval peat diggings termed 'broads') (Fig. 1a). The River Bure is $87 \mathrm{~km}$ in length, flows south-east towards Breydon Water estuary at Great Yarmouth, and has a mean discharge of $6 \mathrm{~m}^{3} \cdot \mathrm{s}^{-1}$ into the North Sea. The Rivers Ant and Thurne are 27 and $11 \mathrm{~km}$ in length, respectively. The study area encompassed approximately $60 \mathrm{~km}$ of river length (not including lateral connections to lakes; Fig. 1a), with channel widths of $25-40 \mathrm{~m}$ and depths of $1.5-3.0 \mathrm{~m}$. The system is tidal, with the upper limit of saline incursion providing the boundary between the 
Fig. 1 Map of the northern Norfolk Broads study system, comprising the Rivers Bure, Ant and Thurne and numerous connected lakes and dyke systems. The locations of acoustic receivers in the Upper Bure (orange), Lower Bure (green), River Ant (brown) and River Thurne (purple) reaches are displayed, as are the locations of two temperature loggers. The rectangle in (a) indicates the spatial extent of the Wroxham-Horning river section illustrated in (b). Channel widths are not to scale

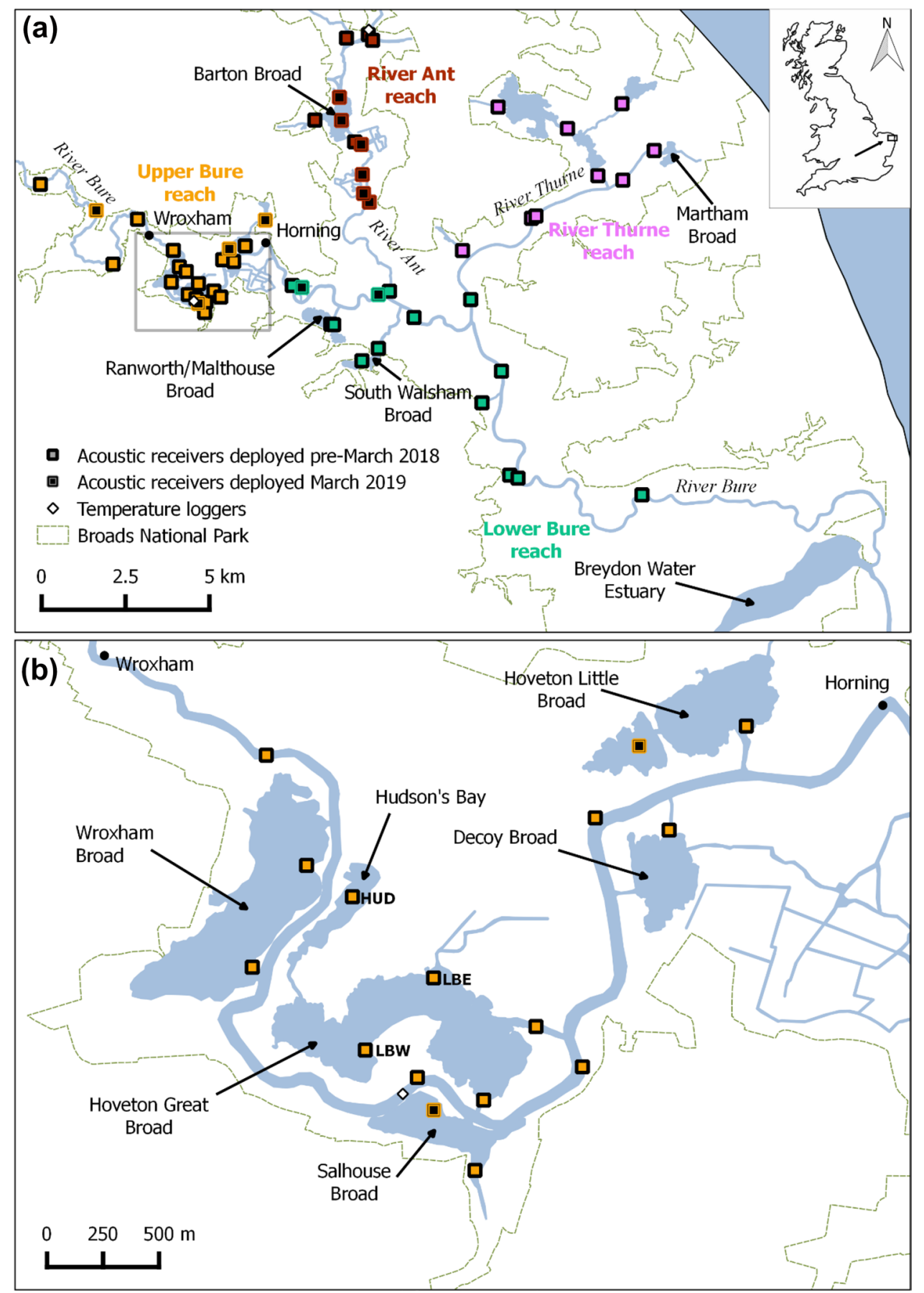

Upper Bure and Lower Bure reaches (at Horning; Fig. 1a; Clarke 1990).

Between the urban centres of Wroxham and Horning (Fig. 1b), river banks are characterised by wet woodland, chiefly alder carr, with small patches of reedbed and a high density of laterally connected broads and dyke systems. This 'Wroxham-Horning' section of the Upper Bure reach has been identified as important for overall fish population density as well as bream spawning, based on the availability of suitable macrophyte substrate within off-channel refugia
(Hindes 2019), high abundance of adult fish during spawning periods and high egg densities (Online resources 1-3). The habitat then transitions to a semi-artificial landscape of open, reed-fringed grazing marshes in the Lower Bure. The River Ant is similar in character to the Upper Bure reach and features extensive marsh dyke systems, while the River Thurne is more open and includes abundant areas of reedbed, alongside the largest of the broads (Hickling Broad, 140 ha, Fig. 1). The Thurne is brackish due to underground exchange between the sea and the catchment's groundwater 
(Pallis 1911) and is at particularly high risk of blooms of Prymnesium parvum, an algal species toxic to fish (Holdway et al. 1978), although it has the highest abundance and species richness of aquatic macrophytes across the study area (Broads Authority 2019). Piscivorous fish (e.g. Northern pike Esox lucius), birds (e.g. cormorant Phalacrocorax spp.) and mammals (e.g. otter Lutra lutra) are present throughout the study system. Bream spawning migrations of up to $25 \mathrm{~km}$ have been documented from the Rivers Thurne and Ant to Hoveton Great Broad and the surrounding Upper Bure area (HGB: Fig. 1b; Winter et al. 2021a). Consequently, analyses were largely focused on the movements of bream within the Wroxham-Horning river section during their reproductive period.

\section{Fish sampling and acoustic telemetry}

A total of 181 bream were captured and tagged between November 2017 and September 2018 across four reaches of the study system; Upper Bure, Lower Bure, Thurne and Ant (Fig. 1a; Table 1). All fish were captured by rod and line angling, as more general fish sampling methods (e.g. fyke netting, seine netting, electric fishing) were too inefficient in such large, open waterbodies (Radinger et al. 2019). Compared to electrofishing, rod and line angling can lead to greater impacts on bream behaviour post-sampling, however any effects are short-term ( $<5$ days; Gardner et al. 2015). Bream were measured (fork length; $\pm 1 \mathrm{~mm}$ ) and, where possible, sexed. Sex was determined by inspecting characteristics of the fish, such as their body shape and secondary sexual characteristics, such as the presence of spawning tubercles on the head, where the latter indicates a male fish (Poncin et al. 2011). These features are most distinct in bream close to their spawning period and, consequently, we considered sex determination to be most reliable for bream sampled in spring (Table 1).

Acoustic transmitters ('tags') were sourced from Vemco (V13: length $36 \mathrm{~mm} \times$ diameter $13 \mathrm{~mm}, 6.0 \mathrm{~g}$ mass in water, $N=148$; V9: length $27.5 \mathrm{~mm} \times$ diameter $9 \mathrm{~mm}, 2.7 \mathrm{~g}$ mass in water, $N=9$ ) and Thelma Biotel (ID-LP13: length $28 \mathrm{~mm} \times$ diameter $13 \mathrm{~mm}, 5.5 \mathrm{~g}$ mass in water, $N=24)$. Tags operated at $69 \mathrm{kHz}$, with battery lives of between 29 and 46 months, and with random transmission intervals between 60 and 120 s ensuring that adjacent signals did not continuously overlap and cause interference. Tags were surgically implanted into the ventral body cavity of the fish, anterior to the pelvic fins and incisions were closed with a single suture and wound sealer. All regulated procedures were performed with the fish under general anaesthesia (Tricaine methanesulfonate, MS-222), following ethical review and under the UK Home Office project licence 70/8063. Fish were released close to their capture location following their return to normal body orientation and swimming behaviour.

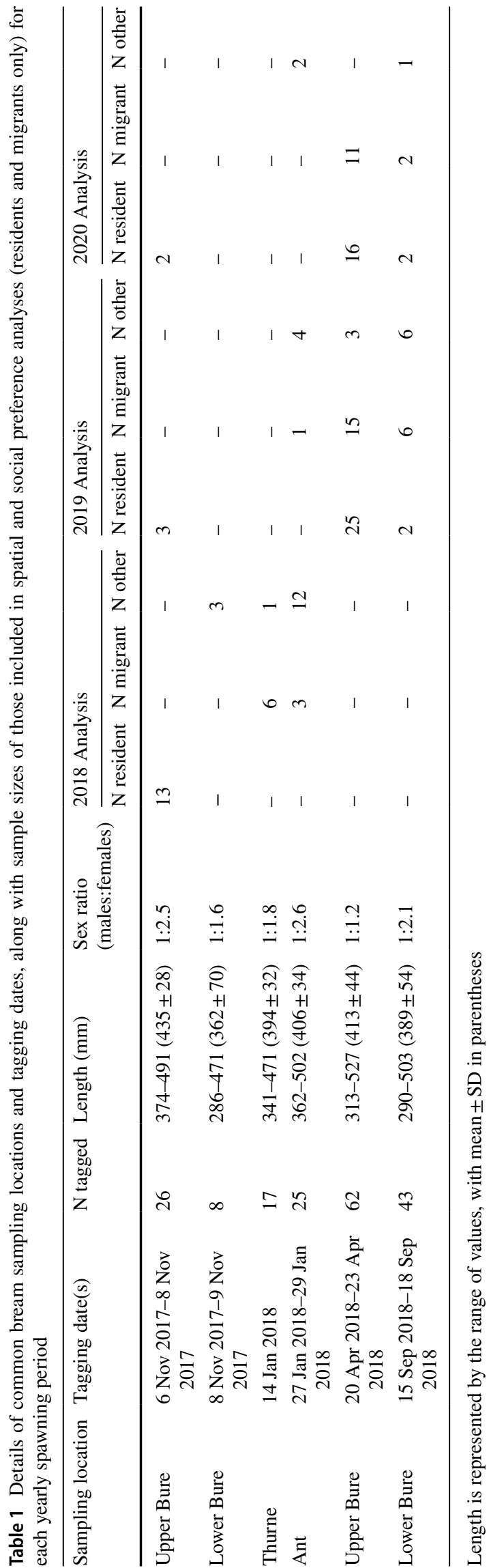


Their movements were then monitored within an array of receivers for up to 2.5 years (to 30 June 2020), encompassing three reproductive periods in the years 2018-2020.

As part of a wider research programme, a fixed array of 44 acoustic receivers (Vemco, VR2W) was installed in October 2017 and January 2018 throughout the four reaches of the study system (Fig. 1a), prior to the first bream reproductive period in spring 2018. Receiver locations were selected based on a combination of factors including maintenance of good $(\leq 5 \mathrm{~km})$ resolution in the main river channels and monitoring of lateral fish movements to/from lakes and dykes. A further 12 receivers were deployed in March 2019 to expand the monitored area (Fig. 1a). Receivers were mostly moored on posts or underwater structures and placed in the channel margins at approximately mid-water depth. Data were downloaded every 3 months, while batteries were replaced annually. Receiver detection range varied with local environmental conditions, but rarely fell below channel width distance (Winter et al. 2021b).

\section{Environmental data}

Water temperature $\left( \pm 0.5^{\circ} \mathrm{C}\right)$ was recorded at hourly intervals by two data loggers in the Rivers Bure and Ant (HOBO ${ }^{\circledR}$ Pendant; model MX2202, Onset Computer Corporation; Fig. 1a). A linear regression model revealed that temperature in the River Ant was a highly significant predictor of temperature in the River Bure $\left(F_{1,5733}=776,600\right.$, $\left.p<0.001, R^{2}=0.99\right)$. Analyses principally used temperature data from the River Bure, however, where this was unavailable (post November 2019), River Bure temperature was estimated according to the linear equation: Bure $=(0.99 \times$ Ant $)-0.21$.

\section{Data preparation}

The telemetry dataset was divided into reproductive periods and non-reproductive periods. In each year, the reproductive period was considered to commence on the first day when water temperature in the River Bure reached $9{ }^{\circ} \mathrm{C}$, the rationale being that off-channel areas tended to be approximately $1{ }^{\circ} \mathrm{C}$ warmer than the main river channel, and this threshold likely captures bream movements just prior to the initiation of spawning at $\geq 12{ }^{\circ} \mathrm{C}$ (Backiel and Zawisza 1968). The reproductive period was considered to have terminated once the final migrant fish (see below) left the Upper Bure reach in a downstream direction. Telemetry data from non-spawning periods were used to classify bream movement type but were otherwise excluded from further analyses. In addition, any bream that entered or were lost to the study during the spawning period were removed from the dataset for that year. This included fish whose acoustic detections ceased or became stationary, and for the 2018 dataset, included all bream tagged in April 2018 (Table 1).

\section{Classification of movement type}

Movement type was defined as follows: bream that overwintered (between 1 December and 28/29 February) exclusively in the Upper Bure reach and were then detected in the Upper Bure during the defined spring spawning period were classified as 'resident'; bream that overwintered either exclusively or partially outside the Upper Bure reach, but were then detected in the Upper Bure during the spring spawning period were classified as 'migrant' (Fig. 2). A $t$ test and chisquared test assessed whether fish length or sex differed by movement type (residency/migration). Bream that did not enter the Upper Bure reach during the spawning period were classified 'other' (Fig. 2).

\section{Spatial preferences}

The number of detections at each receiver gave an initial indication of 'hotspots' of bream activity. Detection count (minus false detections and detections from stationary tags) was scaled relative to the spatial area monitored by each receiver when detection range equalled $200 \mathrm{~m}$. This was visualised for the year 2019 when sample sizes were greatest (Table 1) and when passive acoustic telemetry was supplemented by manual tracking and spawning surveys (Environment Agency, unpublished data; Online Resources 1-3). A measure of acoustic noise, the mean daily noise quotient, (Simpfendorfer et al. 2008) was calculated from summary data stored by the receivers and visualised alongside detection count. Negative values of the noise quotient indicated tag collisions, while positive values indicated ambient/ anthropogenic/biotic noise.

Resident and migrant fish were then linked to the offchannel sites they visited in the Wroxham-Horning area in 'bipartite' networks. Bipartite networks are those in which nodes are one of two types, in this case individual fish or sites, and network edges can only connect nodes of differing types. In these bipartite networks, edges connected fish to sites at which they were detected on a presence/absence basis. Separate networks were generated for each year. The sites examined were Wroxham Broad (WB; two receivers), Salhouse Broad (SB; two receivers), Hoveton Great Broad and Hudson's Bay (HGB; three receivers not including those on broad entrances), Decoy Broad (DB; 1 receiver) and Hoveton Little Broad (HLB; two receivers) (Fig. 1b). However, SB was removed from the 2018 analysis due to concerns about the receiver detection range overlapping with the River Bure, with this receiver subsequently moved by approximately $100 \mathrm{~m}$ in August 2018 and, therefore, included in the 2019 and 2020 analyses. Site nodes were 
(a) Resident
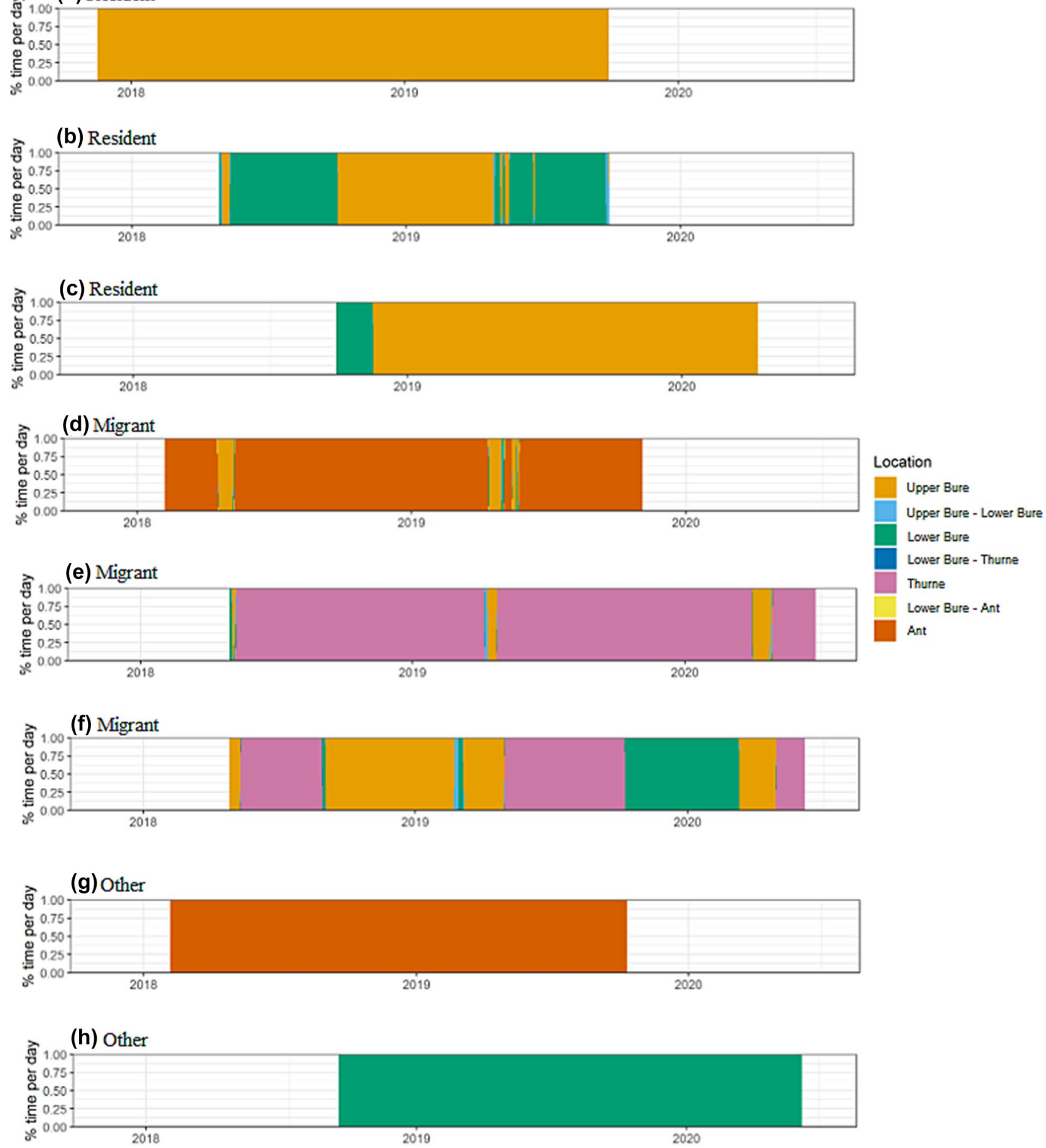

Fig. 2 Example individual trajectories according to river reach of eight common bream Abramis brama tagged in the River Bure study system. Residents (a-c) overwintered exclusively in the Upper Bure reach, while migrants $(\mathbf{d}-\mathbf{f})$ overwintered either partially or exclu-

ranked according to common network metrics; 'degree' indicated the number of edges connected to a node (number of fish visiting), and 'betweenness' gave a measure of sively outside the Upper Bure, prior to their detection in the Upper Bure during the spring reproductive period. Fish classified other ( h) did not visit the Upper Bure during the spring reproductive period

centrality based on the number of shortest paths travelling through a node (Farine and Whitehead 2015). For fish nodes, a generalised linear mixed model (GLMM) tested whether 
movement type (resident/migrant) and year predicted node degree (number of sites visited). This required a Poisson family structure, with fish ID included as a random effect. Between-individual variance was consistently estimated as zero, so random effects were dropped from the model and data tested using a generalised linear model (GLM).

\section{Social preferences}

Bream co-occurrence was examined at the receiver(s) located at the highest-ranking site in the bipartite networks. The co-occurrence of individuals was defined as their simultaneous detection at the same receiver within the same hourly timestep. Detections at each receiver were examined separately, as were the years of study. Hourly timesteps greatly exceeded an acoustic tag's transmission delay, minimising the risk of false negatives, where fish were potentially not detected due to tag collisions or being slightly out of receiver detection range. Sampled timesteps were separated by intervals of 1-2 $\mathrm{h}$ to allow for re-organisation of the network and avoid temporal autocorrelation. Interval length alternated between 1 and $2 \mathrm{~h}$ so that timesteps were not continually sampled at the same time each day. Fish detected in 5 or more of the sampled timesteps were retained for cooccurrence analysis.

The strengths of association between individuals throughout each spawning period were then calculated using the Simple Ratio Index (SRI), where the number of timesteps that two fish co-occurred at a receiver was divided by the total number of timesteps where at least one of the individuals was detected at the same receiver. SRI ranged between 0 and 1 , where 0 indicated individuals never co-occurred and 1 indicated they always co-occurred. SRI association strengths were accumulated into an association matrix, or network. To test if the observed association network was more differentiated than expected at random (i.e. more preferred/ avoided associations), the coefficient of variation (CV) of edge weights (SRIs) was compared to the CV of 50,000 randomised networks. Randomisation was achieved by rearranging the observed pre-network data stream, where with each permutation two individuals were swapped between co-occurrences, and the SRI association network was recalculated (Farine 2017). A $p$ value was calculated as the proportion of times the $\mathrm{CV}$ of the observed network was less than the $\mathrm{CV}$ of the randomised networks.

A multiple regression quadratic assignment procedure (MRQAP), a method of matrix logistic regression for network data (Dekker et al. 2007), was used to test the influence of individual similarity between bream (length, sex, movement type) on their association strength. The SRI association network represented the dependent variable, while similarity matrices represented independent variables. Similarity was assessed on a binary scale, where a value of 1 indicated paired individuals were of the same sex, length class or movement type, and a value of 0 indicated their attributes differed. Length classes were defined as per the mean length and SD of the tagged population; small: $<360 \mathrm{~mm}$ (<mean - SD), medium: $360-450 \mathrm{~mm}$ (mean \pm SD), large: $>450 \mathrm{~mm}(>$ mean $+\mathrm{SD})$. Null models were built from the data stream permutations described previously and applied using the mrqap.custom.null function within the asnipe package (Farine 2019) in R 4.0.2 (R Core Team 2020). Statistical analyses and data formatting also utilised the packages igraph (Csardi and Nepusz 2006) and actel (Flávio 2020).

\section{Results}

The three bream spawning periods were 26 March to 16 May 2018, 20 March to 26 May 2019 and 26 March to 17 May 2020. In 2019, peaks of telemetry activity in Hudson's Bay (Fig. 1b) on 24-25 April and 16-19 May corresponded with direct observations of bream spawning activity (Online Resources 1-3). After applying data restrictions, the 2018 dataset comprised the movements of 13 resident and nine migrant bream (of 76 tagged), while the 2019 dataset comprised 30 residents and 22 migrants (of 181 tagged), and the 2020 dataset comprised 20 residents and 13 migrants (of 181 tagged; Table 1). Loss of bream from the study was higher than expected by natural mortality alone, but we provide evidence to suggest tagging date and tag expulsion were contributing factors (Winter et al. 2020). For fish detected in multiple years, including those classified 'other' $(n=40)$, $88 \%$ were consistent in their type of movement behaviour (resident/migrant/other) across years. This included 36 bream that were detected in two consecutive years and four that were detected in three consecutive years. Across all resident and migrant individuals, length did not differ by sex ( $t$ test: $t_{67}=0.37, p=0.72$ ), and, excluding bream showing flexible movement behaviour between years, length did not differ by movement type $\left(t_{67}=0.49, p=0.63\right)$. Sex ratios of detected fish (males: females) were 1:1.4 in 2018, 1:1.5 in 2019 and 1:2.6 in 2020. Sex did not predict migratory tendency $\left(\chi^{2}=1.16, p=0.28\right)$, including for those fish tagged in April 2018 (Table 1), for which sex determination was most reliable $\left(\chi^{2}=1.15, p=0.28\right)$.

\section{Spatial preferences}

The total number of detections was highest for receivers situated in the Wroxham-Horning section of the Upper Bure, but was also relatively high at Ranworth/Malthouse Broad (Lower Bure), South Walsham Broad (Lower Bure), Barton Broad (River Ant) and close to Martham Broad (River Thurne) (Figs. 1 and 3). Detections at Ranworth/Malthouse 


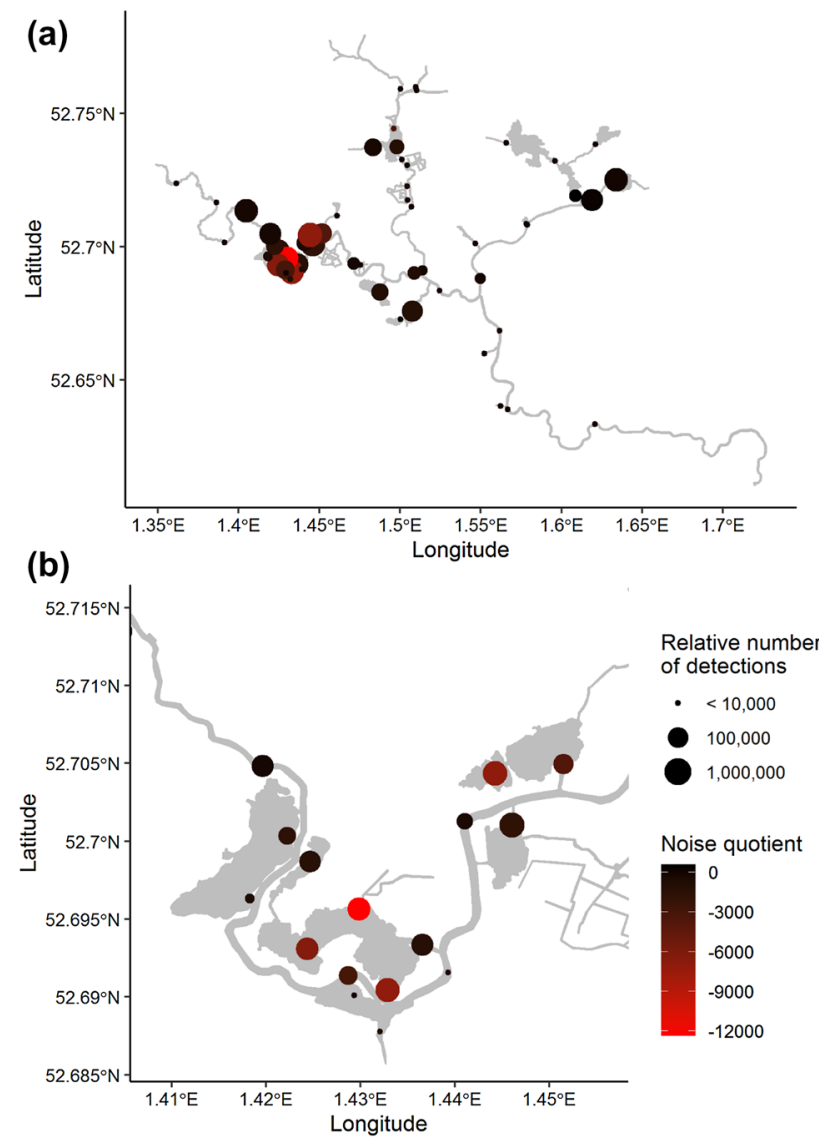

Fig. 3 Total number of detections at each acoustic receiver during the 2019 spawning period $\mathbf{a}$ across the entire study area and $\mathbf{b}$ in the Wroxham-Horning section of the Upper Bure reach. Detections are scaled relative to the detection area of each receiver when detection range $=200 \mathrm{~m}$. Points are coloured according to the mean daily noise quotient, with values $<0$ indicating interference by tag collisions. Detections for fish classified 'resident', 'migrant' and 'other' are combined. See electronic supplementary material for detection plots specific to movement type (Online Resource 4-6)

Broad and Barton Broad were largely attributed to bream classified 'other' that did not visit the Upper Bure reach during the spawning period, while detections at Martham Broad were principally made by 'migrant' fish and those at South
Walsham Broad were made by both 'migrant' and 'other' fish (Table 1; Online Resources 4-6). Daily noise quotients ranged from $-30,699$ to 3478 , with $59 \%$ of values lower than zero, indicating reduced receiver performance due to tag collision interference. This was particularly evident for receivers within Hoveton Great Broad (HGB), where detection count was likely considerably underestimated (Fig. 3).

In the Wroxham-Horning river section, HGB consistently ranked highest of the site nodes in the bipartite networks according to degree and betweenness in all years (Table 2; Fig. 4), indicating it was visited by the most fish and was the most central site within the networks. The GLM testing movement type on the number of sites visited in the Wroxham-Horning river section was significant, indicating that residents typically visited fewer off-channel sites than migrants during the spawning period (Table 3 ). However, the spatial preferences of residents versus migrants did not significantly differ, with no relationship found between behavioural type and the number of fish detected at each site (2018: $\chi^{2}=1.39, p=0.71 ; 2019: \chi^{2}=9.20, p=0.06 ; 2020$ : $\left.\chi^{2}=8.28, p=0.08\right)$.

\section{Social preferences}

Co-occurrence analyses focused on the three acoustic receivers situated at HGB, excluding those located at the entrances to the broad (LBE, LBW and HUD; Fig. 1b). A total of nine SRI association networks were examined across all years (Fig. 5). In each network, fish nodes of opposite length class, sex and movement type were connected by edges, indicating the co-occurrence of bream with differing attributes at the same receivers within the same hourly timesteps (Fig. 5). The null hypothesis that bream associated randomly was rejected for seven of the networks ( $p \leq 0.001)$, but at LBE and LBW in 2018, the observed coefficient of variation (CV) was not significantly different to random $(p=0.20-0.30$; Fig. 5). This indicated that bream largely formed more preferred associations than expected at random. In some instances, MRQAP tests suggested that length, sex and/or movement type were important predictors of association
Table 2 Off-channel sites in the Upper Bure ranked according to degree (number of fish detected) and betweenness (measure of centrality) calculated from bipartite networks

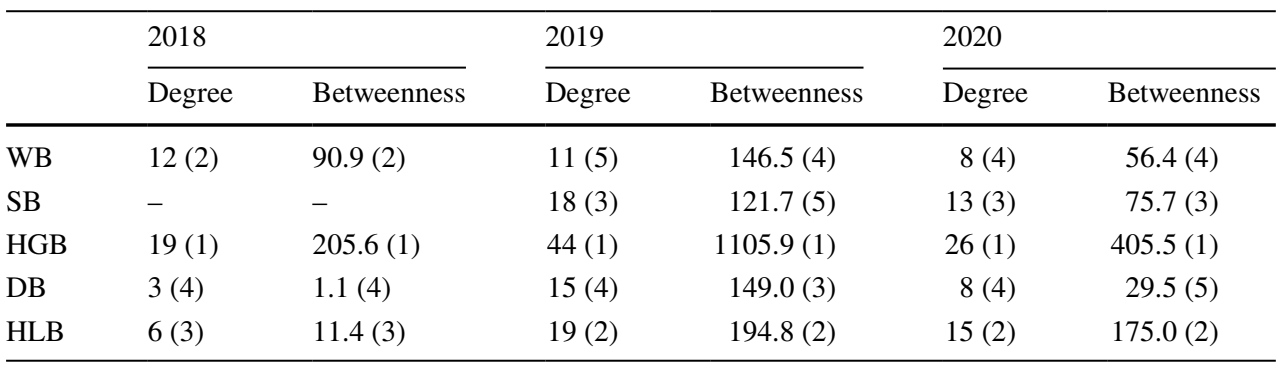

Rankings are provided in parentheses

$W B$ Wroxham Broad; $S B$ Salhouse Broad; $H G B$ Hoveton Great Broad; $D B$ Decoy Broad; $H L B$ Hoveton Little Broad 

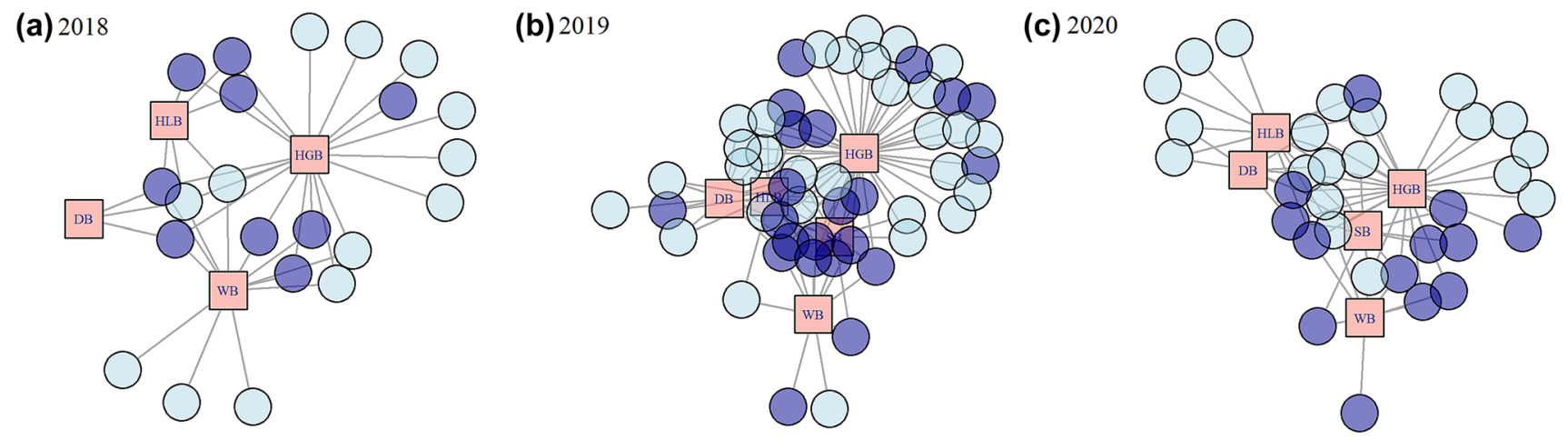

Fig. 4 Bipartite networks of bream (circular nodes) linked to offchannel sites (square nodes) on a presence/absence basis according to year of study. Circular node shading depicts bream movement type

Table 3 Coefficient estimates $( \pm \mathrm{SE})$ for the GLM predicting number of sites visited according to movement type and year

\begin{tabular}{lc}
\hline Parameter & \multicolumn{1}{l}{ Fixed } \\
\hline (Intercept) & $0.76 \pm 0.17^{* * *}$ \\
Type: Resident & $-0.29 \pm 0.14^{*}$ \\
Year: 2019 & $0.12 \pm 0.19$ \\
Year: 2020 & $0.16 \pm 0.20$ \\
\hline
\end{tabular}

Estimates for migrants and the year 2018 are represented by the intercept

$* * * p<0.001 ; * p<0.05$

strength (Table 4), however, given poor adjusted $R^{2}$ values and small effect sizes $(<0.05)$, the influence of these variables on the probability of co-occurrence at each of the receivers and in each year was considered relatively low.

\section{Discussion}

Through applying passive acoustic telemetry in a wellconnected wetland system, this study revealed a high consistency in the movement phenotypes of common bream and revealed that, despite residents and migrants being spatially segregated in non-reproductive periods, they did mix in space and time during their reproductive period. The potential for their interbreeding during spawning was thus considered to be high, suggesting that the different phenotypes detected in the Upper Bure reach comprised a single population that converged at particular off-channel sites to reproduce on an annual basis. Combined with bream that spawn outside the Upper Bure reach (classified 'Other'), these diverse phenotypes appear to form a metapopulation across the Norfolk Broads study area. (light blue $=$ resident; dark blue $=$ migrant $). W B$ Wroxham Broad; $S B$ Salhouse Broad; $H G B$ Hoveton Great Broad; $D B$ Decoy Broad; $H L B$ Hoveton Little Broad

The tagged bream showed high consistency in their movement behaviour (residency/migration) across the three annual reproductive periods. Brodersen et al. (2014) also documented high individual consistency in the movement phenotype of $R$. rutilus, with a high somatic condition increasing the likelihood of individuals adopting the migration strategy (see also Brodersen et al. 2008). Conversely, evidence suggests that habitat shifts of bream are more likely to occur in fish of low somatic condition (Brodersen et al. 2019), although how condition during juvenile development and maturation affected the subsequent behaviour of the adult fish here was unable to be tested. Indeed, behaviourally plastic traits in early life may become canalised and fixed in certain individuals, dependent on genetic and environmental threshold states (Chapman et al. 2012a; Brodersen et al. 2014). Consequently, adopting long-term studies on the movements of bream that encompass both their juvenile and adult life stages would be helpful in identifying the ecological mechanisms by which individuals adopt different behavioural strategies. There are, however, technological issues to overcome here relating to the type of tags used, and their lifespan and suitability for implanting into juvenile fish. Notwithstanding, studies increasingly suggest that some smaller tags can be used on relatively small fish without long-term detrimental impacts on their growth and survival (Crossin et al. 2017; Klinard et al. 2018).

There was no statistical difference in the lengths of migrant and resident bream at tagging. Evidence from other studies suggests that smaller individuals (across the length range of $100-550 \mathrm{~mm}$ ) have a higher propensity to migrate between habitats (Skov et al. 2011). That such an effect was not detected in the present study could have been an artefact of the study design, as the use of the acoustic tags precluded the tagging of fish below $290 \mathrm{~mm}$. Whilst the findings of Skov et al. (2011) imply that bream movement occurs across a gradient of predation risk, predators of bream are present 
(a)

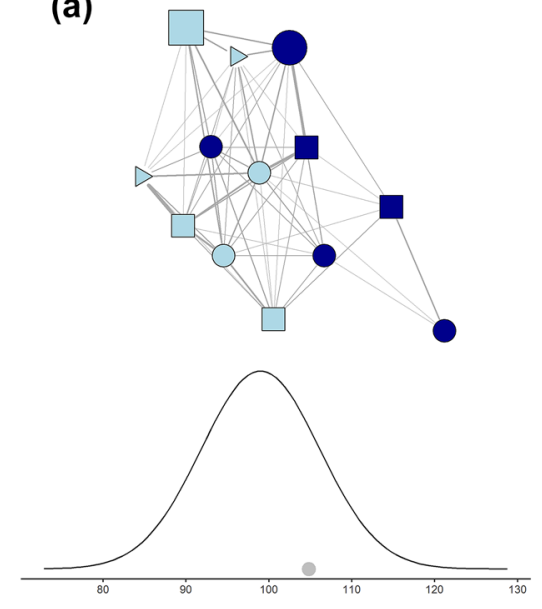

(d)
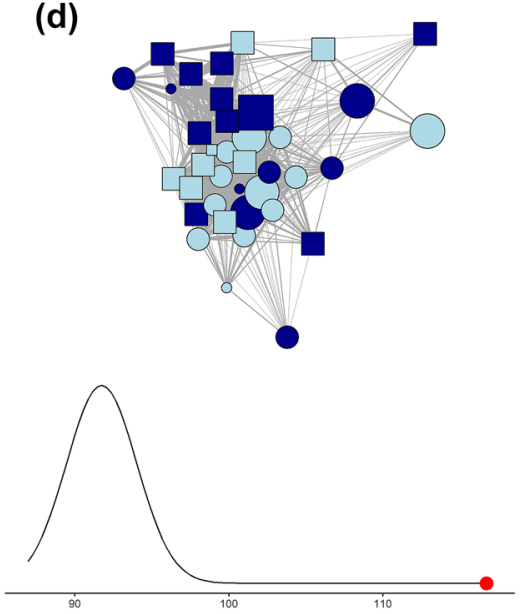

(g)
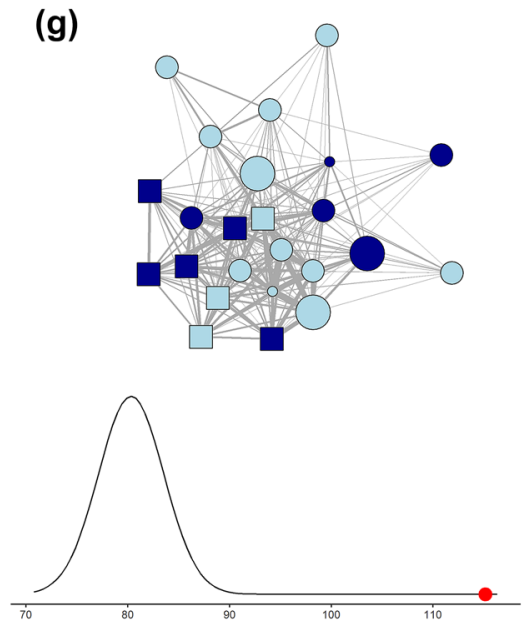

(b)
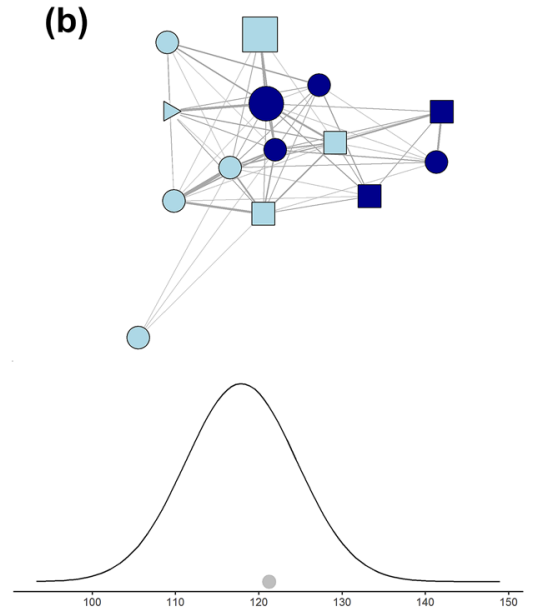

(e)
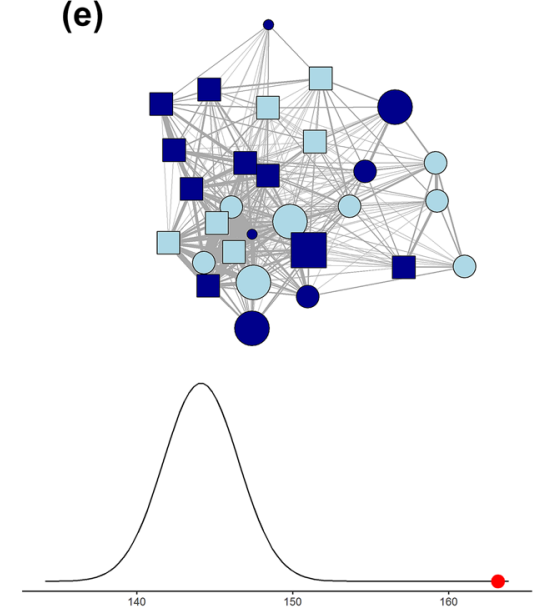

(h)
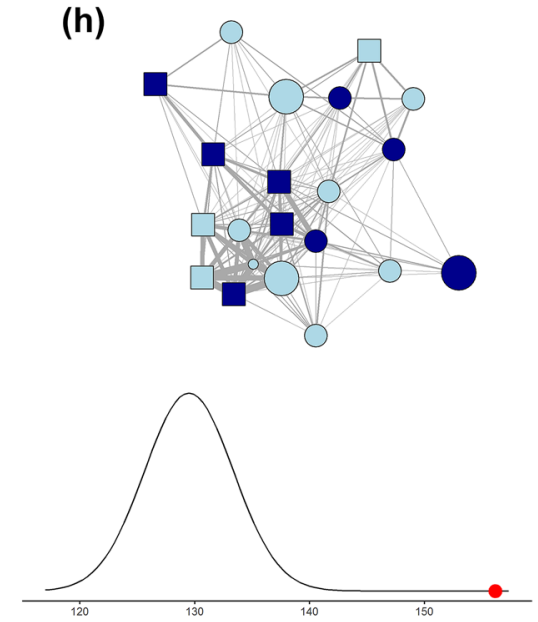

(c)

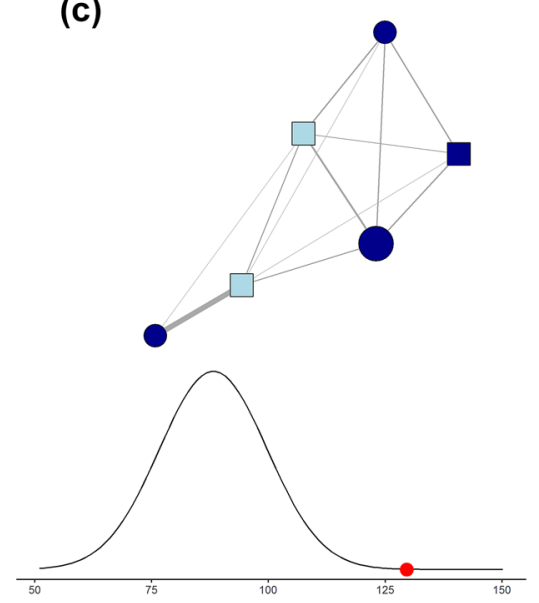

(f)
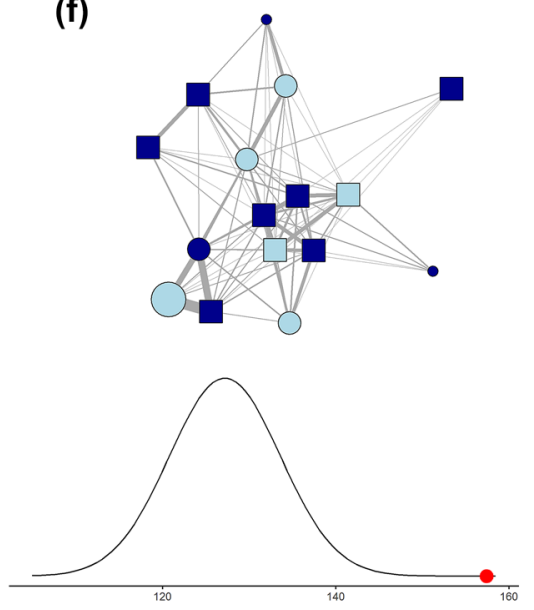

(i)
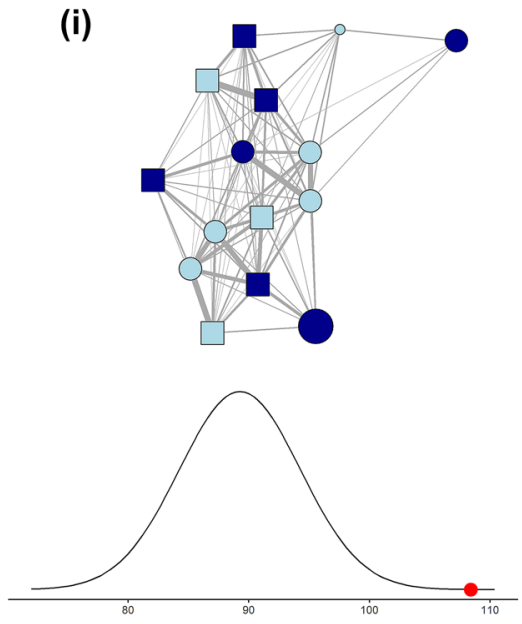

Fig. 5 Common bream association networks at receivers located within Hoveton Great Broad: LBE (left; a, d, g), LBW (centre; b, e, h) and HUD (right; c, f, i) in the years 2018 (top; a, b, c), 2019 (middle; d, e, f) and 2020 (bottom; g, h, i). Edge thickness is proportional to SRI values. Node shading depicts movement type (light blue =resident; dark blue $=$ migrant $)$, node shape depicts fish sex ( square $=$ male circle $=$ female $;$ triangle $=$ not determined $)$ and node size depicts fish size (small: $<360 \mathrm{~mm}$; medium: $360-450 \mathrm{~mm}$; large: $>450 \mathrm{~mm}$ ). Each panel displays the observed network (top) and the normal probability density plot for the coefficient of variation (CV) values of the 50,000 random networks (bottom). In the density plots, values of the observed $\mathrm{CV}$ are indicated by dots (red $=$ statistically significant; grey $=$ non-significant) 
Table 4 Results of the Multiple Regression Quadratic Assignment Procedures (MRQAPs) indicating the influence of bream similarity in length, sex and movement type on their association strength in each year and at each receiver (LBE; LBW; HUD) within the Hoveton Great Broad complex (Fig. 1b)

\begin{tabular}{|c|c|c|c|c|c|c|}
\hline Year & Receiver & $\begin{array}{l}\mathrm{N} \text { bream in } \\
\text { network }\end{array}$ & Predictors & $\begin{array}{l}\text { Regression Coef- } \\
\text { ficient }(\beta)\end{array}$ & $P(|\beta| \leq|r|)$ & Adjusted $R^{2}$ \\
\hline \multirow[t]{3}{*}{2018} & HUD & 6 & Length & -0.007 & 0.92 & -0.06 \\
\hline & & & Sex & -0.036 & 0.046 & \\
\hline & & & Type & -0.030 & 0.24 & \\
\hline \multirow[t]{9}{*}{2019} & LBE & 38 & Length & -0.005 & $<0.001$ & 0.008 \\
\hline & & & Sex & 0.005 & 0.044 & \\
\hline & & & Type & 0.021 & $<0.001$ & \\
\hline & LBW & 29 & Length & -0.0008 & 0.77 & -0.005 \\
\hline & & & Sex & 0.009 & $<0.001$ & \\
\hline & & & Type & 0.003 & 0.11 & \\
\hline & HUD & 16 & Length & 0.022 & 0.39 & 0.001 \\
\hline & & & Sex & 0.007 & 0.99 & \\
\hline & & & Type & -0.016 & 0.012 & \\
\hline \multirow[t]{9}{*}{2020} & LBE & 24 & Length & -0.012 & 0.72 & 0.020 \\
\hline & & & Sex & -0.0007 & 0.88 & \\
\hline & & & Type & 0.019 & $<0.001$ & \\
\hline & LBW & 21 & Length & -0.018 & 0.28 & 0.003 \\
\hline & & & Sex & -0.005 & 0.89 & \\
\hline & & & Type & 0.010 & 0.027 & \\
\hline & HUD & 15 & Length & 0.045 & $<0.001$ & 0.038 \\
\hline & & & Sex & 0.005 & 0.36 & \\
\hline & & & Type & 0.002 & 0.75 & \\
\hline
\end{tabular}

Regression coefficients (log odds) were considered significant (in bold) if greater than the null expectancy, thus when $P(|\beta| \leq|r|)<0.05$. Receivers LBE and LBW were not included in the 2018 analysis as the SRI association networks were not considered significantly different to random throughout the Norfolk Broads study area. This suggests that the partial migration observed here was driven less by predation vulnerability and perhaps more likely by trophic polymorphism, where migrants that overwinter in the brackish reaches of the study area (i.e. the Lower Bure and River Thurne) will specialise on different prey to those in upstream areas (Chapman et al. 2012a). A recent study suggested that the diet composition of bream is sex specific, although this did not coincide with sexual segregation in habitat use (Žák et al. 2020). While we found no relationship between migratory phenotype and sex, migration in other fish species is often more common in females, particularly for anadromous salmonids (Jonsson and Jonsson 1993). Common bream, being a shoaling species, differ to salmonids in their social behaviour, which could explain the absence of an effect of sex on migratory status. Instead, bream migration may be more dependent on a flexible extrinsic state, such as dominance or body condition, which could be related to population density or resource availability (Chapman et al. 2012a).

In most cases, the co-occurrence of bream at acoustic receivers was not random, suggesting the existence of distinct shoals, with certain individuals more likely to be detected simultaneously than expected by chance. This is in line with their known gregarious nature (Backiel and Zawisza 1968). However, the probability of co-occurrence was not strongly correlated with similarity in fish length, sex or movement type (resident/migrant). Other species of shoaling fishes can show strong segregation by sex and/or body size, including during spawning, for example Atlantic cod (Morgan and Trippel 1996). Others may be grouped according to behavioural type, which may link to physiological differences, such as activity levels or environmental tolerances (Killen et al. 2017). One possibility not examined here is the segregation of fish by relatedness, which may be more relevant during reproductive periods than at other times of the year (Ward et al. 2020). Assortative mating could be contributing to phenotypic expression, however, the acoustic telemetry technology used here was unsuitable for monitoring fine-scale spatial $(<1 \mathrm{~m})$ and temporal $(<5 \mathrm{~s})$ interactions between fish. Elsewhere, assortative mating is thought to influence the genetic and morphological divergence of roach and European perch Perca fluviatilis across the littoral-pelagic axis (Faulks et al. 2015). Thus, newly available advanced positioning telemetry could be applied to testing this in wild bream (Guzzo et al. 2018; Leander et al. 2020).

It is highly likely that detection count was underestimated where acoustic interference due to tag collisions was high. Sporadic use of mobile tracking and side scan sonar imaging in the Wroxham-Horning reach during 2019 confirmed that, 
where bream were densely aggregated, tag collisions contributed to missed and false acoustic transmissions (Environment Agency, unpublished data). There exists a trade-off between maximising the temporal resolution of acoustic tracking (by reducing transmission delay) and minimising the risk of tag collisions (by increasing transmission delay) (Simpfendorfer et al. 2015). Similarly, the risk of tag collisions increases with the sample size of tagged fish. For example, with a random transmission interval $\sim 90 \mathrm{~s}$ and an acoustic pulse time of $\sim 3 \mathrm{~s}$ (time required to transmit signal), an aggregation of 30 tagged individuals within range of one receiver could result in almost continuous interference. Thus, without the use of controls (e.g. fixed-location sentinel tags), metrics dependent on receiver performance should be interpreted with caution (Payne et al. 2010). However, a new digital coding system, with a transmission time of $<1 \mathrm{~s}$, is less sensitive to acoustic noise and shows potential for more efficient monitoring of dense aggregations of tagged animals (Guzzo et al. 2018; Leander et al. 2020).

During the reproductive period, resident and migrant bream co-occurred in space and time, indicating the potential for their interbreeding. This lack of spawning segregation implies unrestricted gene flow between behavioural phenotypes, although genetic differentiation could still drive differences in behaviour, for example through postzygotic selection against resident-migrant hybrids (Turbek et al. 2018) or complex epigenetic processes (Merlin and Liedvogel 2019). Nevertheless, the genetic isolation of residents and migrants is unlikely, but these inferences would be strongly complemented by population genetic analyses. Ultimately, the phenotypic diversity observed here likely promotes long-term population stability through buffering against site-specific mortality due to environmental fluctuations (Chapman et al. 2012a). For example, should the component of the bream population that resides in the lower, brackish reaches be impacted by saline intrusion (BBC 2014), or a toxic bloom of Prymnesium parvum (ITV 2015), the subsequent production of migrants from the upper reaches would be predicted to recolonise these affected areas (Pickett and White 1985).

The presence of different migratory strategies within populations of cyprinid fishes is becoming increasingly evident, with the phenotypic diversity demonstrated in this bream population being similar to that detected in populations of other cyprinid species, such as $R$. rutilus (Chapman et al. 2012b; Brodersen et al. 2014). Thus, where high habitat connectivity has been maintained in freshwater systems, then life-history strategies that encompass partial migration are usually preserved. Yet evidence suggests that globally, there are few rivers that remain free flowing throughout their length (Grill et al. 2019) and in Great Britain, only 3.3\% of the total river network remains fully connected (Jones et al. 2019). Consequently, if it is considered that maintaining this phenotypic diversity in cyprinid species is an ecological and conservation priority, given its potential importance for maintaining genetic diversity and population stability, then this can only be achieved by prioritising the maintenance and/ or restoration of functional habitat connectivity in lowland river systems.

Supplementary Information The online version contains supplementary material available at https://doi.org/10.1007/s00027-021-00804-9.

Acknowledgements We gratefully acknowledge the support for EW of the EU LIFE+ Nature and Biodiversity Programme: LIFE14NAT/ $\mathrm{UK} / 000054$, as well as funding and resource support from the Environment Agency. Thanks also to the local angling community for their considerable support with fish sampling.

Author contributions EW, AH, SL and RB conceived the ideas, designed methodology and collected the data; EW analysed the data and led the writing of the manuscript. All authors contributed critically to the drafts and gave final approval for publication

Data availability The datasets generated and analysed here will be available from the author upon reasonable request.

\section{Declarations}

Conflict of interest The authors have no conflict of interests to declare

Ethics statement All regulated procedures were performed following ethical review and under the UK Home Office project licence 70/8063.

Open Access This article is licensed under a Creative Commons Attribution 4.0 International License, which permits use, sharing, adaptation, distribution and reproduction in any medium or format, as long as you give appropriate credit to the original author(s) and the source, provide a link to the Creative Commons licence, and indicate if changes were made. The images or other third party material in this article are included in the article's Creative Commons licence, unless indicated otherwise in a credit line to the material. If material is not included in the article's Creative Commons licence and your intended use is not permitted by statutory regulation or exceeds the permitted use, you will need to obtain permission directly from the copyright holder. To view a copy of this licence, visit http://creativecommons.org/licenses/by/4.0/.

\section{References}

Augspurger JM, Warburton M, Closs GP (2017) Life-history plasticity in amphidromous and catadromous fishes: a continuum of strategies. Rev Fish Biol Fisheries 27:177-192

Backiel T, Zawisza J (1968) Synopsis of biological data on the bream: Abramis brama (L.). FAO Fisheries Synopsis 36:1-116

Baerwald MR, Meek MH, Stephens MR, Nagarajan RP, Goodbla AM, Tomalty KM, Thorgaard GH, May B, Nichols KM (2016) Migration-related phenotypic divergence is associated with epigenetic modifications in rainbow trout. Mol Ecol 25:1785-1800

BBC. 2014. Tidal surge kills thousands of fish. https://www.bbc.co. uk/news/uk-england-norfolk-29756260, Accessed 30 Jul 2020. 
Berejikian BA, Bush RA, Campbell LA (2014) Maternal control over offspring life history in a partially anadromous species, Oncorhynchus mykiss. Trans Am Fish Soc 143:369-379

Broads Authority (2019) Broads Annual Water Plant Monitoring Report. https://www.broads-authority.gov.uk/

Brodersen J, Nilsson PA, Hansson L-A, Skov C, Brönmark C (2008) Condition-dependent individual decision-making determines cyprinid partial migration. Ecology 89:1195-1200

Brodersen J, Nicolle A, Nilsson PA, Skov C, Bronmark C, Hansson LA (2011) Interplay between temperature, fish partial migration and trophic dynamics. Oikos 120:1838-1846

Brodersen J, Chapman BB, Nilsson PA, Skov C, Hansson L-A, Brönmark C (2014) Fixed and flexible: coexistence of obligate and facultative migratory strategies in a freshwater fish. PLoS ONE 9:e90294

Brodersen J, Hansen JH, Skov C (2019) Partial nomadism in largebodied bream (Abramis brama). Ecol Freshw Fish 28:650-660

Chapman B, Hulthén K, Brodersen J, Nilsson PA, Skov C, Hansson LA, Brönmark C (2012a) Partial migration in fishes: causes and consequences. J Fish Biol 81:456-478

Chapman B, Skov C, Hulthén K, Brodersen J, Nilsson PA, Hansson LA, Brönmark C (2012b) Partial migration in fishes: definitions, methodologies and taxonomic distribution. J Fish Biol 81:479-499

Clarke K (1990) Salt water penetration into the Upper Bure. Norfolk Norwich 28:381

Crossin GT, Heupel MR, Holbrook CM, Hussey NE, Lowerre-Barbieri SK, Nguyen VM, Raby GD, Cooke SJ (2017) Acoustic telemetry and fisheries management. Ecol Appl 27:1031-1049

Csardi G, Nepusz T (2006) The igraph software package for complex network research. InterJournal, complex systems 1695:http:// igraph.org. Accessed 2 Sept 2020

Debes PV, Piavchenko N, Erkinaro J, Primmer CR (2020) Genetic growth potential, rather than phenotypic size, predicts migration phenotype in Atlantic salmon. Proc R Soc B 287:20200867

Dekker D, Krackhardt D, Snijders TA (2007) Sensitivity of MRQAP tests to collinearity and autocorrelation conditions. Psychometrika 72:563-581

Dingle H (1996) Migration: the biology of life on the move. Oxford University Press, New York, Oxford

Farine DR (2017) A guide to null models for animal social network analysis. Methods Ecol Evol 8:1309-1320

Farine DR (2019) asnipe: animal social network inference and permutations for ecologists. R package version 1.1.12: https://CRAN.Rproject.org/package=asnipe. Accessed 3 Sept 2020

Farine DR, Whitehead H (2015) Constructing, conducting and interpreting animal social network analysis. J Anim Ecol 84:1144-1163

Faulks L, Svanbäck R, Eklöv P, Östman Ö (2015) Genetic and morphological divergence along the littoral-pelagic axis in two common and sympatric fishes: perch, Perca fluviatilis (Percidae) and roach, Rutilus rutilus (Cyprinidae). Biol J Lin Soc 114:929-940

Ferguson A, Reed TE, Cross TF, McGinnity P, Prodöhl PA (2019) Anadromy, potamodromy and residency in brown trout Salmo trutta: the role of genes and the environment. J Fish Biol 95:692-718

Flávio H (2020) actel: acoustic telemetry data analysis. R package version 1.0.0.9023: https://github.com/hugomflavio/actel. Accessed 18 June 2020

Gardner CJ, Deeming DC, Wellby I, Soulsbury CD, Eady PE (2015) Effects of surgically implanted tags and translocation on the movements of common bream Abramis brama (L.). Fish Res 167:252-259

Grabowski TB, Thorsteinsson V, McAdam BJ, Marteinsdóttir G (2011) Evidence of segregated spawning in a single marine fish stock: sympatric divergence of ecotypes in Icelandic cod? PLoS ONE. https://doi.org/10.1371/journal.pone.0017528
Grill G, Lehner B, Thieme M, Geenen B, Tickner D, Antonelli F, Babu S, Borrelli P, Cheng L, Crochetiere H (2019) Mapping the world's free-flowing rivers. Nature 569:215-221

Guzzo MM, Van Leeuwen TE, Hollins J, Koeck B, Newton M, Webber DM, Smith FI, Bailey DM, Killen SS (2018) Field testing a novel high residence positioning system for monitoring the fine-scale movements of aquatic organisms. Methods Ecol Evol 9:1478-1488

Hansen JH, Skov C, Baktoft H, Brönmark C, Chapman BB, Hulthén K, Hansson LA, Nilsson PA, Brodersen J (2019) Ecological consequences of animal migration: prey partial migration affects predator ecology and prey communities. Ecosystems. https://doi.org/10. 1007/s10021-10019-00402-10029

Hindes A (2019) Bream spawning habitat assessment: Hoveton Great Broad and environs. Norwich UK, Natural England, Dragonfly House, $\mathrm{p} 11$

Hodge BW, Wilzbach MA, Duffy WG, Quiñones RM, Hobbs JA (2016) Life history diversity in Klamath River steelhead. Trans Am Fish Soc 145:227-238

Holdway P, Watson R, Moss B (1978) Aspects of the ecology of Prymnesium parvum (Haptophyta) and water chemistry in the Norfolk Broads, England. Freshwater Biol 8:295-311

ITV. 2015. Toxic algae killing thousands of fish on the Norfolk Broads. https://www.itv.com/news/anglia/2015-04-15/toxic-algae-killingthousands-of-fish-on-the-norfolk-broads, Accessed 30 Sep 2020.

Jones J, Börger L, Tummers J, Jones P, Lucas M, Kerr J, Kemp P, Bizzi S, Consuegra S, Marcello L (2019) A comprehensive assessment of stream fragmentation in Great Britain. Sci Total Environ 673:756-762

Jonsson B, Jonsson N (1993) Partial migration: niche shift versus sexual maturation in fishes. Rev Fish Biol Fisheries 3:348-365

Jorgensen SJ, Reeb CA, Chapple TK, Anderson S, Perle C, Van Sommeran SR, Fritz-Cope C, Brown AC, Klimley AP, Block BA (2010) Philopatry and migration of Pacific white sharks. Proc R Soc B Biol Sci 277:679-688

Kennedy M, Fitzmaurice P (1968) The biology of the bream Abramis Brama (L) in Irish waters. Proc R Irish Aca Sec B Biol Geo Chem Sci 67:95-157

Killen SS, Marras S, Nadler L, Domenici P (2017) The role of physiological traits in assortment among and within fish shoals. Phil Trans R Soc B Biol Sci 372:20160233

Klinard NV, Halfyard EA, Fisk AT, Stewart TJ, Johnson TB (2018) Effects of surgically implanted acoustic tags on body condition, growth, and survival in a small, laterally compressed forage fish. Trans Am Fish Soc 147:749-757

Leander J, Klaminder J, Jonsson M, Brodin T, Leonardsson K, Hellström G (2020) The old and the new: evaluating performance of acoustic telemetry systems in tracking migrating Atlantic salmon (Salmo salar) smolt and European eel (Anguilla anguilla) around hydropower facilities. Can J Fish Aquat Sci 77:177-187

Merlin C, Liedvogel M (2019) The genetics and epigenetics of animal migration and orientation: birds, butterflies and beyond. Journal of Experimental Biology 222.

Montorio L, Evanno G, Nevoux M (2018) Intra-and interspecific densities shape life-history traits in a salmonid population. Oecologia 188:451-464

Morgan M, Trippel E (1996) Skewed sex ratios in spawning shoals of Atlantic cod (Gadus morhua). ICES J Mar Sci 53:820-826

Natural England. 2020. Designated Sites View. https://designatedsites. naturalengland.org.uk/ Accessed on 23 Jul 2020.

Pallis M (1911) On the cause of the salinity of the Broads of the River Thurne. Geograph J 37:284-291

Payne NL, Gillanders BM, Webber DM, Semmens JM (2010) Interpreting diel activity patterns from acoustic telemetry: the need for controls. Mar Ecol Prog Ser 419:295-301 
Phillips G, Jackson R (1990) The control of eutrophication in very shallow lakes, the Norfolk Broads. Verhandlungen des Internationalen Verein Limnologie 24:573-575

Pickett STA, White PS (1985) The ecology of natural disturbance and patch dynamics. Academic Press, Orlando, FL

Pinder L (1997) Research on the Great Ouse: overview and implications for management. Regul Rivers Res Manage 13:309-315

Poncin P, Matondo BN, Termol C, Kestemont P, Philippart J-C (2011) Relationships between circulating androgens, aggressive behaviour and breeding tubercles in males of the common bream Abramis brama L. in an aquarium environment. Fish Physiol Biochem 37:533-542

R Core Team (2020) R: A language and environment for statistical computing. R Foundation for Statistical Computing, Vienna, Austria

Radinger J, Britton JR, Carlson SM, Magurran AE, Alcaraz-Hernández JD, Almodóvar A, Benejam L, Fernández-Delgado C, Nicola GG, Oliva-Paterna FJ (2019) Effective monitoring of freshwater fish. Fish Fish 20:729-747

Robichaud D, Rose GA (2004) Migratory behaviour and range in Atlantic cod: inference from a century of tagging. Fish Fish 5:185-214

Simpfendorfer CA, Heupel MR, Collins AB (2008) Variation in the performance of acoustic receivers and its implication for positioning algorithms in a riverine setting. Can J Fish Aquat Sci 65:482-492

Simpfendorfer CA, Huveneers C, Steckenreuter A, Tattersall K, Hoenner X, Harcourt R, Heupel MR (2015) Ghosts in the data: false detections in VEMCO pulse position modulation acoustic telemetry monitoring equipment. Anim Biotelem 3:55

Skov C, Baktoft H, Brodersen J, Brönmark C, Chapman BB, Hansson L-A, Nilsson PA (2011) Sizing up your enemy: individual predation vulnerability predicts migratory probability. Proc Royal Soc B Biol Sci 278:1414-1418
Turbek SP, Scordato ES, Safran RJ (2018) The role of seasonal migration in population divergence and reproductive isolation. Trends Ecol Evol 33:164-175

Ward AJ, Kent MI, Webster MM (2020) Social recognition and social attraction in group-living fishes. Front Ecol Evol. https://doi.org/ $10.3389 /$ fevo.2020.00015

Whelan K (1983) Migratory patterns of bream Abramis brama L. shoals in the River Suck System. Irish Fish Investig Series A 23:11-15

Whitlock SL, Campbell MR, Quist MC, Dux AM (2018) Using genetic and phenotypic comparisons to evaluate apparent segregation among kokanee spawning groups. Trans Am Fish Soc 147:43-60

Winter ER, Hindes AM, Lane S, Britton JR (2020) Predicting the factors influencing the inter-and intraspecific survival rates of riverine fishes implanted with acoustic transmitters. J Fish Biol 97:1209-1219

Winter ER, Hindes AM, Lane S, Britton JR (2021a) Movements of common bream Abramis brama in a highly-connected, lowland wetland reveal subpopulations with diverse migration strategies. Freshwater Biol. In press

Winter ER, Hindes AM, Lane S, Britton JR (2021b) Detection range and efficiency of acoustic telemetry receivers in a connected wetland system. Hydrobiologia 848:1825-1836

Žák J, Prchalova M, Šmejkal M, Blabolil P, Vašek M, Matěna J, Ríha M, Peterka J, Sed’a J, Kubečka J (2020) Sexual segregation in European cyprinids: consequence of response to predation risk influenced by sexual size dimorphism. Hydrobiologia 847:1439-1451

Publisher's Note Springer Nature remains neutral with regard to jurisdictional claims in published maps and institutional affiliations. 